\title{
Evaluation of seismic reflector slopes with a Yoyo-CTD
}

\author{
G. Krahmann, ${ }^{1}$ C. Papenberg, ${ }^{1}$ P. Brandt, ${ }^{1}$ and M. Vogt ${ }^{1}$ \\ Received 30 April 2009; revised 17 June 2009; accepted 15 July 2009; published 21 August 2009.
}

[1] In spring 2007 a dedicated seismic and oceanographic experiment was conducted in the Gulf of Cadiz. Employing two research vessels seismic and hydrographic observations were made contemporaneously and in close proximity. At a 12 hour long station inside a Meddy a conductivitytemperature-depth (CTD) probe was lowered and raised repeatedly while the seismic vessel conducted a repetitive survey on tracks nearby. Over the period 17 CTD profiles were collected covering the depth interval from 500 to $1700 \mathrm{~m}$. The CTD data show the Meddy's elevated temperatures and salinities as well as varying intrusive features. When converted into reflection coefficients and convoluted with the seismic source signal the CTD data agrees well with nearby seismic data. The comparison of the temporal/spatial slopes of CTD-derived reflectors with those of isopycnals shows a good agreement when the slopes are determined over intervals shorter than 4 hours. Citation: Krahmann, G., C. Papenberg, P. Brandt, and M. Vogt (2009), Evaluation of seismic reflector slopes with a Yoyo-CTD, Geophys. Res. Lett., 36, L00D02, doi:10.1029/2009GL038964.

\section{Introduction}

[2] Over the past years Seismic Oceanography (SO) has seen much interest in the geophysics and oceanography communities [Holbrook et al., 2003; Nandi et al., 2004; Nakamura et al., 2006; Krahmann et al., 2008]. During this time it has become clear that the proper evaluation of SO requires direct comparisons of seismic data with high accuracy hydrographic observations. Some combined observations have since been planned and executed [e.g., Nakamura et al., 2006; Hobbs, 2007; W. S. Holbrook, personal communication, 2009]. Data from one of these, a collaboration of the EU funded experiment Geophysical Oceanography (GO) with a complementary German experiment, is presented here.

[3] For a meaningful comparison of hydrographic and seismic data it is necessary to understand how seismic reflection data is related to hydrographic properties such as temperature, salinity, and density. To obtain the latter at high accuracy in parallel with seismic data requires measurements from two independent platforms, as the seismic vessel is at most capable of deploying expendable, low accuracy hydrographic instruments such as XBTs and XCTDs at the same time as it collects seismic data. Another research vessel provides for the greatest flexibility and has been realized during GO, but an autonomous underwater vehicle or, albeit with limitations to the simultaneity, an autonomous glider could also be employed.

\footnotetext{
${ }^{1}$ Leibniz Institute of Marine Sciences, IFM-GEOMAR, Kiel University, Kiel, Germany.

Copyright 2009 by the American Geophysical Union. 0094-8276/09/2009GL038964\$05.00
}

[4] In a number of experiments and publications it has been shown that synthetic seismic data derived from hydrographic measurements agrees well with seismic data observed in temporal and spatial proximity [Nandi et al., 2004; Nakamura et al., 2006]. Lacking a second observing platform these comparisons have to date been either limited to expendable, low accuracy probes deployed simultaneously with the seismic survey or to higher accuracy CTD casts collected before or after the seismic survey. Here we present data from a two-ship experiment during which CTD casts and seismic observations were performed in closest possible spatial and temporal proximity. In particular we analyze and compare data from a Yoyo-CTD station with one of several parallel seismic tracks. The experiment took place in April/May 2007 off Cape St. Vincent in the Gulf of Cadiz (see Figure 1). This region is well known for the Mediterranean outflow that enters the North Atlantic through the Strait of Gibraltar and follows the Iberian shelf break as a deep boundary current [Bower et al., 1997]. At some topographic features the current can become unstable and detach from the coast to form isolated rotating lenses of Mediterranean water (Meddies). The boundary current and the Meddies carry water that is warmer and more saline than the surrounding water masses. These differences form a regime in which double diffusive processes and interleaving of the different water masses create sharp vertical contrasts in characteristic acoustic impedance that are reflective to seismic sounds. Such a regime is particularly suited to the evaluation and application of SO methods.

[5] After this introduction we describe the data sets and their processing. We then compare the two independent sets of observations and after establishing their similarity continue with an analysis of the slopes of reflectors and isopycnals based on hydrographic data. Finally we summarize our results.

\section{Data and Methods}

[6] Here we present data from one of five seismic sections (GO-LR-08 to GO-LR-12 of the GO project) collected in close proximity (see Figure 1) and at the same time as a Yoyo-CTD station $\left(36^{\circ} 10.5^{\prime} \mathrm{N}, 9^{\circ} 40.4^{\prime} \mathrm{W}\right.$ on May 7 , 2007). This place and time was chosen because it was located inside a Meddy that was observed repeatedly during the ships' campaigns and because the Meddy showed a wealth of spatially variable reflective features. While FS Poseidon was busy with the Yoyo-CTD, RRS Discovery collected the seismic sections.

[7] The CTD system consisted of a Seabird 911+ with a rosette water sampler. Fortyfive water samples were taken during the cruise's 43 CTD and 2 Yoyo-CTD stations and shipped home for salinity calibration measurements. Postprocessing of the CTD data included the correction of sensor delays, correction of conductivities to match lab values, and 


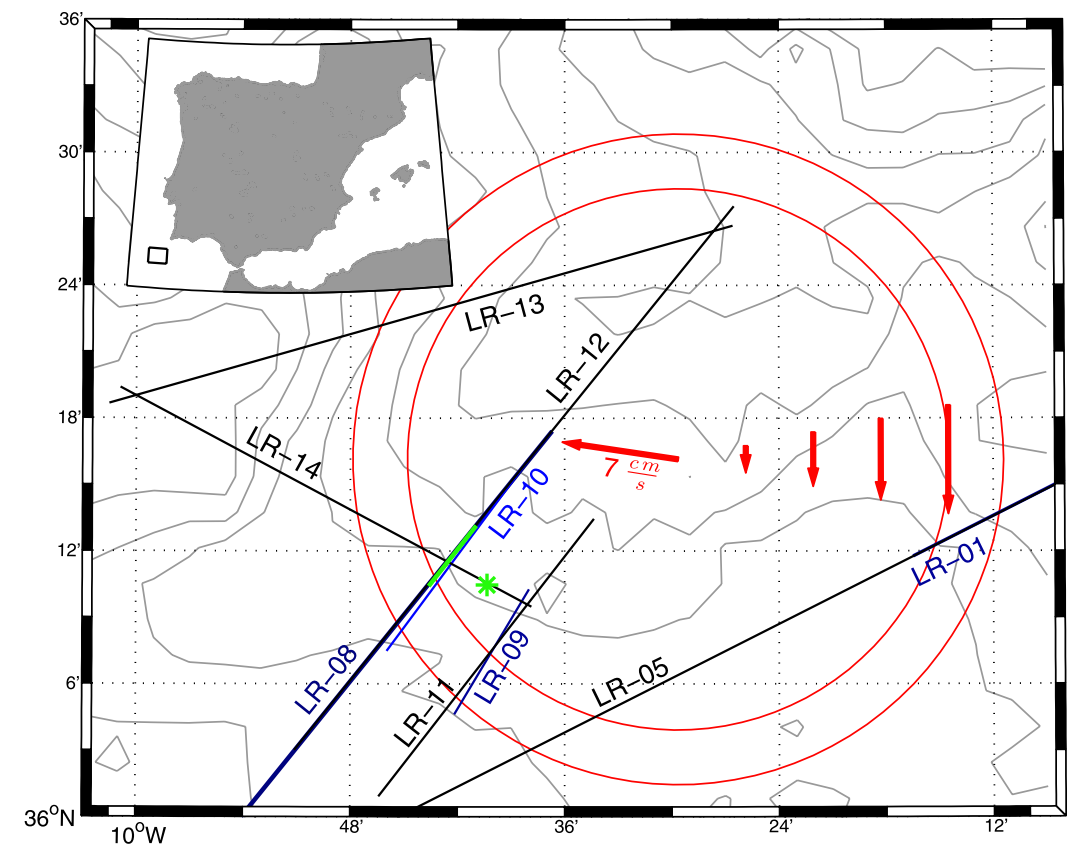

Figure 1. Map with the Yoyo-CTD's (green marker) and the seismic sections' location (blue and black lines and labels) in the Gulf Cadiz. The green line indicates the part of section GO-LR-12 shown in Figure 3b. Two red circles show the Meddy's estimated location during the Yoyo-CTD (the inner circle denotes the Meddy's core, the outer circle includes the zone of intense interleaving). The arrow at the center of the Meddy shows its estimated translation, the four arrows (not to scale) the idealized solid body rotation of the Meddy. Calculations based on the hydrographic fields indicate that the Meddy's maximum velocities were about $25 \mathrm{~cm} / \mathrm{s}$.

averaging and resampling the data onto a 1 dbar grid. Resulting accuracies of temperature and salinity measurements are estimated to be $0.002^{\circ} \mathrm{C}$ and 0.003 , respectively. During the analyzed second Yoyo-CTD station (the first Yoyo-CTD lacked simultaneous seismic observations) the system was lowered 17 times from $500 \mathrm{~m}$ to $1700 \mathrm{~m}$. Temporal spacing between down-casts was 40 minutes and the ship kept position within a $100 \mathrm{~m}$ radius. In our analyses we use only data from the down-casts as data from up-casts has a lower accuracy due to the sensors' position in the wake of the rosette. To simplify our analyses we regridded the hydrographic data shown in Figure 2. First we determined conversions from depth into neutral density space [Jackett and McDougall, 1997] for each of the down-casts. Using 2nd order interpolation we derived the depth of each density layer at a 3 minute resolution. Along these layers we interpolated salinities and temperatures, propagating the hydrographic properties only along isopycnals. Reversing the depth-neutral density conversion, we then interpolated the data back to a regular depth grid to obtain temperatures and salinities with 3 minute temporal and $1 \mathrm{~m}$ depth resolution.

[8] Simultaneous with the hydrographic observations seismic reflection data was acquired from RRS Discovery. Shots, fired every 20 seconds from a $2400 \mathrm{cu}$-inch (38 liter) airgun-array, were recorded with a $2400 \mathrm{~m}$ long 192 channel hydrophone streamer, both towed at a speed of 4 knots. Seismic processing included the removal of the direct water wave, gain recovery, amplitude calibration, and CDP binning $(6.25 \mathrm{~m})$. The seismic sections used in this study were 3D true amplitude pre-stack time migrated.

[9] From the regridded hydrographic data we calculated sound speed, in situ density, and their product, characteristic acoustic impedance $Z$. From the impedance, normal inci- dence reflection coefficients were calculated as $R=\left(Z_{2}-Z_{1}\right)$ $\left(Z_{2}+Z_{1}\right)$, with 2 and 1 denoting the properties above and below a reflecting surface, respectively. This requires the determination of the impedance changes over a certain depth
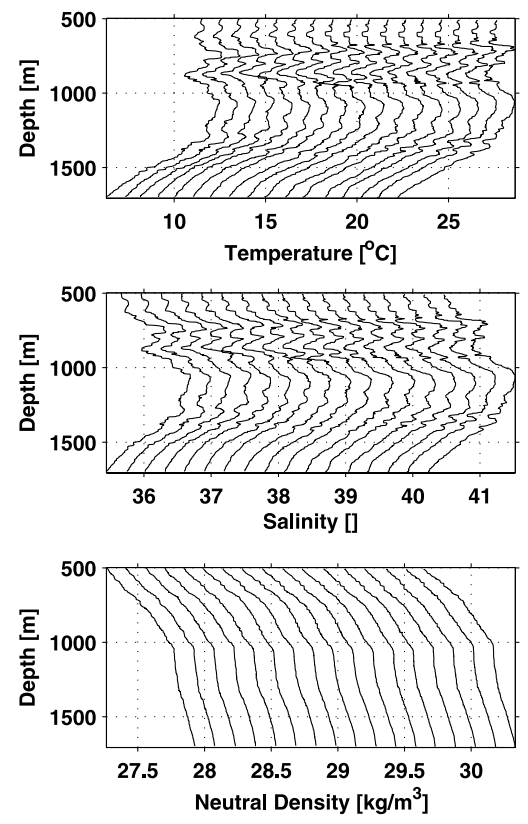

Figure 2. Hydrographic data collected during the 12 hour Yoyo-CTD station. (top) Temperature profiles of the 17 down-casts, offset by $1{ }^{\circ} \mathrm{C}$, (middle) salinity profiles, offset by 0.3 , and (bottom) neutral density profiles, offset by $0.15 \mathrm{~kg} / \mathrm{m}^{3}$. 

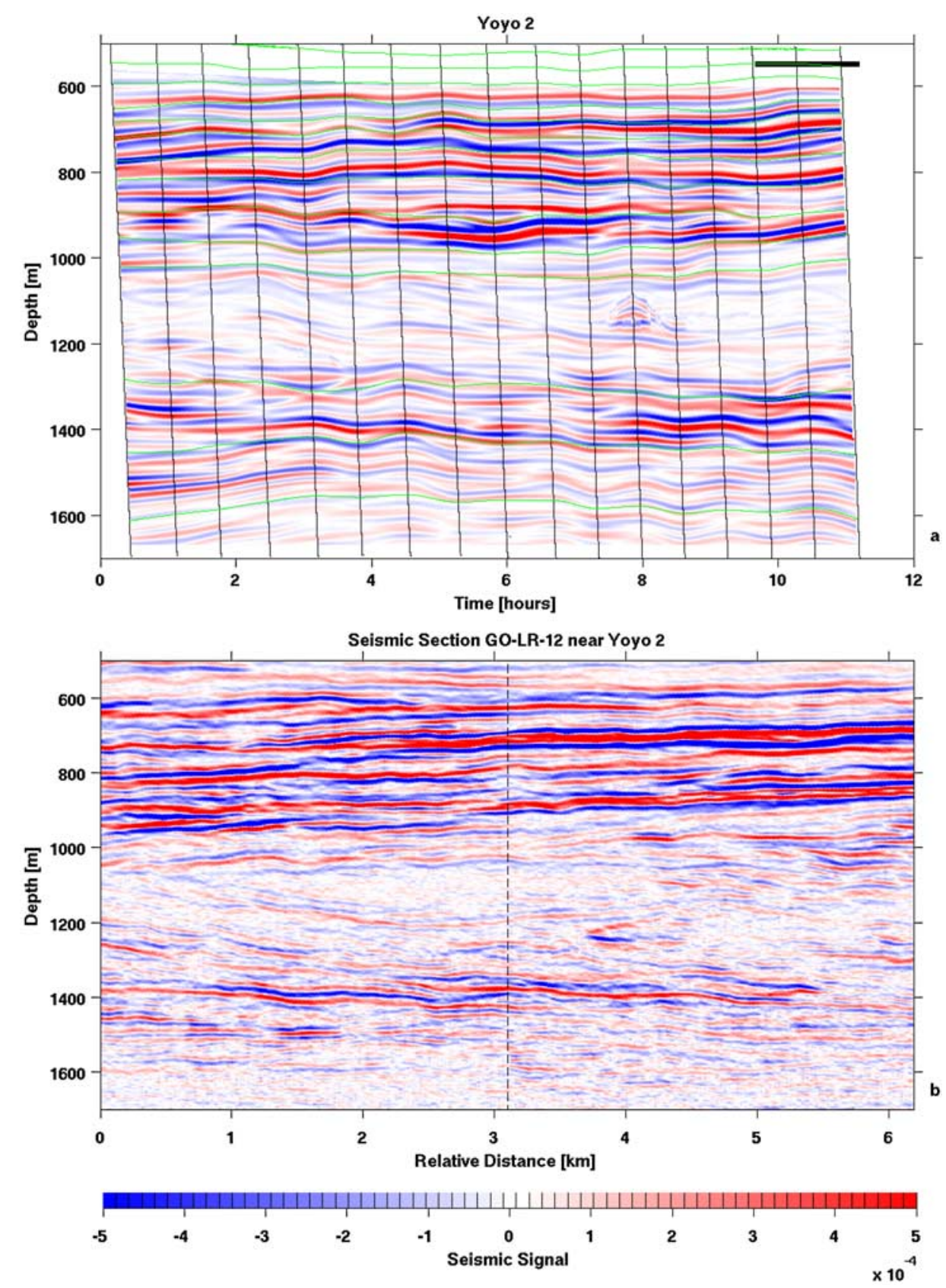

Figure 3. (a) Hydrography-based synthetic seismic section. (b) A part of seismic section GO-LR-12 collected at the same time and in close proximity (see Figure 1). The dashed line in the lower graph marks the time when the two ships were closest. Also indicated in the upper graph are the CTD's depth (black) and neutral density isopycnals (green). The thick black line indicates the timing of GO-LR-12. Waters sampled both by the Yoyo and the seismic section should, however, have passed by the Yoyo's position several hours earlier.

interval. For our purposes we used intervals of $10 \mathrm{~m}$ or about a quarter wavelength of the seismic source signal. We then convoluted the reflection coefficients with the seismic source signal. The resulting synthetic seismic data is shown in Figure $3 \mathrm{a}$ and the nearby observed seismic data in Figure $3 \mathrm{~b}$.

[10] The distinctly different temporal and spatial natures of the observed and the synthetic seismic data sets prevent a direct comparison. While observed seismic data consists of spatial sections collected over several hours, our synthetic seismic data is based on observations made over a comparable time span but at a single location. From the latter it is thus difficult to make qualified statements about horizontal scales of the observed features as they are often used in SO. If we were able to establish a meaningful value for the ocean currents at the Yoyo-CTD's location, we could convert temporal into spatial variations. Unfortunately current observations made by FS Poseidon with lowered and ship-based ADCP systems indicated two problems. First, as can be expected from a subsurface eddy, significant vertical shear of horizontal currents was observed over the depth interval sampled, and second, there was significant temporal variation in the upper $500 \mathrm{~m}$ horizontal currents. No single velocity or 

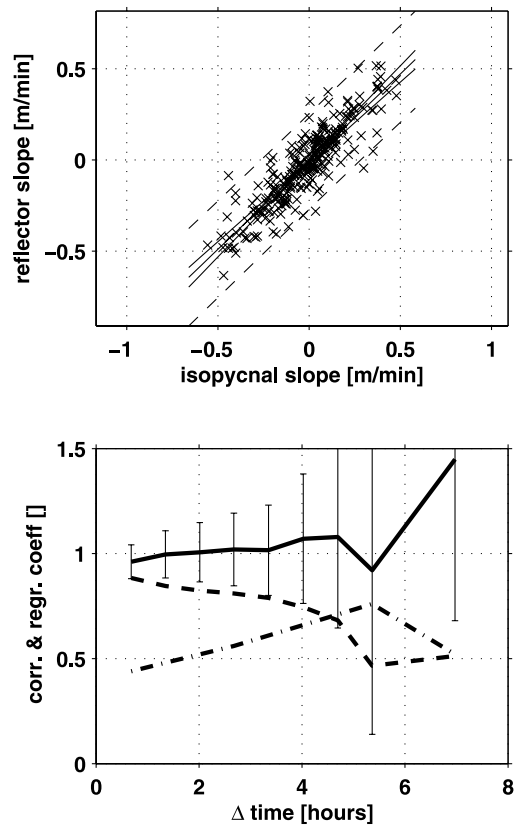

Figure 4. (top) A scatter plot of synthetic reflector slopes against isopycnal slopes, calculated between consecutive Yoyo-CTD casts $(\Delta$ time $=40 \mathrm{~min})$. (bottom) Regression (solid with error-bars) and correlation coefficients (dashed) are shown for all possible time intervals. The dash-dotted line shows the minimum correlation required to reach a $99 \%$ significance level.

velocity profile can thus be ascribed to the Yoyo-CTD and consequently we can not directly relate a time difference to a horizontal distance. Generally we observed current speeds between 0.05 and $0.25 \mathrm{~m} / \mathrm{s}$. Based on these we can only give a ball-park conversion of 1 hour in the Yoyo-CTD to horizontal scales of about 200 to $700 \mathrm{~m}$ (translating into 2 to $8 \mathrm{~km}$ for the entire Yoyo-CTD). The variable current speeds and directions also mean that we cannot connect a profile observed during the Yoyo-CTD to a particular profile in the seismic sections.

[11] A further caveat again arises from the geometry of the Yoyo-CTD observations. Water masses sampled with the Yoyo-CTD can all be considered advectively connected. The Yoyo-CTD thus samples mostly along current bands and not perpendicular to them as the currents move the water masses past the ship's location. At a location inside a Meddy we might thus underestimate the spatial variability by preferring to measure along advectively moving water mass bands. The seismic sections were in contrast chosen to be nearly perpendicular to the Meddy's currents in order to fully cut through the Meddy. Future experiments should thus consider TowYo-CTD stations in which the hydrographic vessel while lowering and raising the CTD slowly steams parallel to the seismic section.

\section{Results and Discussion}

[12] Temperatures and salinities of the Yoyo-CTD (see Figure 2) show the typical pattern of a Meddy with elevated values from about 700 to $1400 \mathrm{~m}$. Density steadily increases down to about $1000 \mathrm{~m}$, followed by a $200 \mathrm{~m}$ thick layer with only little change, the core of the Meddy, and followed again by a slower increase at larger depths. In the vertical, temperatures and salinities vary synchronously while the densities show only little deviations from smooth profiles. That means that the density variations due to temperatures and salinities are largely compensating. Over the 17 casts a fair amount of temporal variations can be seen with intrusion-like features changing their amplitudes or depths or appearing/disappearing altogether. These intrusive features are responsible for a good part of the locally large vertical impedance gradients that are reflectiving the seismic sound.

[13] Next we compare synthetic and observed seismic data (see Figure 3). Both data sets show a $400 \mathrm{~m}$ thick layer with a large number of reflectors above the Meddy's core, a $200 \mathrm{~m}$ thick layer of reflectors below the core, and in the core a zone with only weak, if any, reflectors. Unfortunately, as outlined above, the two data sets image different spatial and temporal aspects of the reflector field and no simple connection between their profiles can be established. A direct comparison is thus not feasible. Qualitatively we do, however, find that observed and synthetic data show very similar reflector patterns and variabilities and thus conclude that our synthetic seismic data can be used for further evaluations.

[14] An open point of discussion in SO has been the relationship between reflectors and isopycnals. Holbrook and Fer [2005] and Krahmann et al. [2008] have, in order to interpret vertical reflector displacements as internal wave excursions, assumed that for horizontal wave lengths up to a few $\mathrm{km}$ reflector and isopycnal depths vary synchronously. After establishing that the synthetic reflectors are comparable to the ones observed nearby we now are able examine the relationship between reflectors and isopycnals in more detail. We first employed the tracking algorithm of Krahmann et al. [2008] to determine the depths of the synthetic reflectors. We found 173 tracks (positive and negative reflectors) that were traceable for longer than one hour. For each of these reflectors we calculated an average neutral density [Jackett and McDougall, 1997] and determined the depth of the respective isopycnal over the time during which the reflector was tracked. We then calculated the temporal/spatial slopes of the reflectors and the neutral density isopycnals between the 17 CTD casts. For the longest possible track/isopycnal observed over all 17 casts this results in 16 slopes over a time difference of 1 cast, 15 over a difference of 2 casts, and so on, and finally 1 slope value over a time difference of 16 casts. Only very few reflectors were continuous over the whole Yoyo-CTD. On average the reflectors could not further be tracked after 2.5 hours or 3.7 casts. We then created scatter plots of the reflector slopes against the slopes of their isopycnals and calculated regression coefficients as a function of the time difference over which the slope was calculated. Please note that the temporal/spatial slopes we determine differ from the intrusion slopes in density space determined by Ruddick [1992]. Vertical displacements of reflectors and isopycnals and the slopes derived from them are on small temporal and spatial scales likely dominated by dynamic processes such as internal waves, which move reflectors and isopycnals synchronously, whereas the intrusion slopes of Ruddick [1992] characterize the difference between reflector and isopycnal slopes.

[15] We find that for time differences up to 4 hours the slopes correlate strongly and the linear regression coefficient 
is about 1 (see Figure 4). For longer differences the correlation falls off and is no longer significant at the $99 \%$ level while the regression coefficient remains about 1 . This indicates that for wave periods shorter than 4 hours or, with the described uncertain time-distance conversion, wave lengths shorter than about 800 to $2800 \mathrm{~m}$ we can use reflectors as a proxy for isopycnals. For longer wave periods/lengths the use of reflectors as isopycnal proxies appears not securely justified. The given limit stems, however, more from the limited duration of the Yoyo-CTD than from regression coefficients deviating significantly from 1 .

\section{Summary}

[16] Data from a Yoyo-CTD and contemporaneously collected seismic data have been analyzed for this study. We found after proper processing that involved the convolution of vertical impedance gradients with the seismic source signal, a good agreement between the Yoyo-CTD's synthetic and nearby observed seismic data. As far as can be determined from the limited temporal resolution and duration of the Yoyo-CTD wave-like reflector undulations observed in seismic data have indeed hydrographic counterparts that originate in temperature and salinity fluctuations. In particular we inspected the relationship between temporal/spatial slopes of reflectors and isopycnals. We found that for temporal differences shorter than about 4 hours the slopes agree well with a high correlation and a linear regression coefficient close to unity. The correlation of reflector and isopycnal slopes lost significance at temporal distances longer than 5 hours, though the regression coefficients were still about 1 . This study thus justifies the use of reflector depth variations as a proxy for isopycnal displacements as long at it is restricted to wave periods shorter than 4 hours or, with the above mentioned caveats, wave lengths shorter than about 800 to $2800 \mathrm{~m}$.

[17] Acknowledgments. We thank the dedicated crews of FS Poseidon and RRS Discovery. This work was supported by Deutsche Forschungsgemeinschaft (grant KR 3488/1-1) and by the EU project GO (grant 15603 NEST).

\section{References}

Bower, A. S., L. Armi, and I. Ambar (1997), Lagrangian observations of Meddy formation during A Mediterranean Undercurrent Seeding Experiment, J. Phys. Oceanogr., 27, 2545-2575.

Hobbs, R. W. (2007), PROJECT: GO-Geophysical Oceanography: A new tool to understand the thermal structure and dynamics of oceans, Eur. Union Newsl., 2, 7, (Available at http://www.aapg.org/europe/newsletters/ 2007/06jun/06jun07europe.pdf).

Holbrook, W. S., and I. Fer (2005), Ocean internal wave spectra inferred from seismic reflection transects, Geophys. Res. Lett., 32, L15604, doi:10.1029/2005GL023733.

Holbrook, W. S., P. Paramo, S. Pearse, and R. W. Schmitt (2003), Thermohaline fine structure in an oceanographic front from seismic reflection profiling, Science, 301, 821-824.

Jackett, D. R., and T. J. McDougall (1997), A neutral density variable for the world's oceans, J. Phys. Oceanogr., 27, 237-263.

Krahmann, G., P. Brandt, D. Klaeschen, and T. Reston (2008), Mid-depth internal wave energy off the Iberian Peninsula estimated from seismic reflection data, J. Geophys. Res., 113, C12016, doi:10.1029/ 2007JC004678.

Nakamura,Y.,T.Noguchi,T.Tsuji,S.Itoh,H.Niino,andT.Matsuoka(2006),(2006), (2006), Simultaneous seismic reflection and physical oceanographic observations of oceanic fine structure in the Kuroshio extension front, Geophys. Res. Lett., 33, L23605, doi:10.1029/2006GL027437.

Nandi, P., W. S. Holbrook, S. Pearse, P. Pramo, and R. W. Schmitt (2004), Seismic reflection imaging of water mass boundaries in the Norwegian Sea, Geophys. Res. Lett., 31, L23311, doi:10.1029/2004GL021325.

Ruddick, B. (1992), Intrusive mixing in a Mediterranean salt lens-Intrusion slopes and dynamical mechanisms, J. Phys. Oceanogr., 22, 1274-1285.

P. Brandt, G. Krahmann, C. Papenberg, and M. Vogt, Leibniz Institute of Marine Sciences, IFM-GEOMAR, Kiel University, Düsternbrooker Weg 20, D-24106 Kiel, Germany. (gkrahmann@ifm-geomar.de) 